Bulletin d'Histoire Contemporaine de

l'Espagne

$50 \mid 2016$

Les intellectuels en Espagne, de la dictature à la démocratie (1939-1986)

\title{
La sonrisa de la política. Dibujantes alrededor de la Segunda República española
}

José Contreras Ruiz

\section{(2) OpenEdition \\ Journals}

Edición electrónica

URL: http://journals.openedition.org/bhce/907

DOI: $10.4000 /$ bhce. 907

ISSN: 1968-3723

\section{Editor}

Presses Universitaires de Provence

\section{Edición impresa}

Fecha de publicación: 1 diciembre 2016

Paginación: 269-271

ISSN: 0987-4135

\section{Referencia electrónica}

José Contreras Ruiz, « La sonrisa de la política. Dibujantes alrededor de la Segunda República española », Bulletin d'Histoire Contemporaine de l'Espagne [En línea], 50 | 2016, Publicado el 09 octubre 2018, consultado el 24 septiembre 2020. URL : http://journals.openedition.org/bhce/907 ; DOI : https://doi.org/10.4000/bhce.907 
La sonrisa de la política. Dibujantes alrededor de la Segunda República española $^{1}$

\section{Josep CONTRERAS RUIZ}

Esta tesis se ha centrado en el estudio del trabajo artístico de los dibujantes satíricos. Éste ha sido tradicionalmente menospreciado y, por tanto, poco estudiado en España, en buena medida porque se ha considerado que su impacto resultaba más visual que informativo, y por ello más efímero. Sin embargo, la acción de trasladar las ideas en imágenes facilita una mayor rapidez comunicativa que, en cualquier caso, permite llegar a un mayor número de personas (tal y como demuestran las grandes tiradas de estas publicaciones), especialmente entre la población que no podía leer o escribir. Además, existe una larga tradición satírica desde el siglo XIX que ha contado paralelamente con un buen número de dibujantes extraordinarios, hecho que hace aún más atractivo su estudio. La tesis se focaliza en el estudio de tres publicaciones satíricas, El Be Negre y DIC (de ámbito catalán), y Gracia y Justicia (de ámbito español), que no habían sido estudiadas anteriormente en profundidad.

Durante la Segunda República española (1931-1936) surgieron nuevas publicaciones satíricas que, como El Be Negre (19311936) y Gracia y Justicia (1931-1936), sobresalieron por su originalidad a la hora de reflejar la actualidad política durante la etapa republicana. Ninguna de estas dos revistas, además, estuvo vinculadas a un partido político en concreto, aunque

1 Tesis de historia leida el 21 de diciembre de 2012, en la Universitat Pompeu Fabra de Barcelona. Directores: Drs. Enric Ucelay-Da Cal y Josep Pich i Mitjana. Tribunal: Dr. Ängel Duarte Montserrar, Universitat de Girona (Presidente); Dr. Josep Sánchez Cervelló, Universitat Rovira i Virgili (Secretario) y Dr. Joan B. Cullà, Universitat Autònoma de Barcelona (Vocal). la mayoría de los integrantes de $\mathrm{El} \mathrm{Be}$ Negre simpatizaran con el ideario político centrista que sostenía el muy minoritario Acció Catalana; este hecho no impidió que la revista se mostrara sumamente crítica con esta organización. El Be Negre, una de las publicaciones más mordaces del siglo pasado, se ganó pronto la complicidad de un gran número de lectores que, quedaba sorprendido tanto por la fuerza de los dibujos como por sus poco convencionales textos. La revista estuvo dirigida por el joven periodista Josep Maria Planes y contó con algunos de los dibujantes catalanes más relevantes de su época, como Valentí Castanys, Francesc Fontanals, Soka o un jovencísimo Avel-lí Artís-Gener, Tísner. Nadie se escapó de las irreverentes críticas de la revista, en especial los militares, la Iglesia y los grupos que se mostraron contrarios al estatuto autonómico.

Por su parte, Gracia y Justicia tampoco mostró una afiliación política concreta, aunque evidenciaba su afinidad con los círculos monárquicos, reaccionarios, anticatalanistas y muy católicos de la extrema derecha madrileña, como el representado por el también muy minoritario Partido Nacionalista Español. En el fondo, la revista se mantuvo como una alternativa periodística de propaganda ideológica que no encontró la manera de articularse como organización política. Su director, el periodista de origen canario Manuel Delgado Barreto, centró las críticas en el conjunto de las izquierdas, ya fuesen españolas o catalanas, en especial en la figura de Manuel Azaña, que se convirtió en una verdadera obsesión para la publicación madrileña. En realidad, la razón del éxito de Gracia y Justicia, por la que hoy en día aún es recordada, se encontraba en la gran calidad artística de sus dibujantes, entre los que destacaron Ricardo García, K-Hito y Antonio Orbegozo.

Una tercera revista satírica singular, todavía hoy poco conocida, fue la catalana 
DIC (1931-1935), Defensa dels Interessos Catalans, propagadora de un fuerte nacionalismo catalán y de un clericalismo católico que complementó con una defensa del republicanismo, hecho no demasiado frecuente en la época. A diferencia de $E l$ Be Negre y Gracia y Justicia, DIC apoyó abiertamente a las organizaciones políticas de la Lliga Regionalista y de la Unió Democràtica de Catalunya. La revista, que siempre mantuvo a sus colaboradores en la sombra del anonimato (aunque se podía entrever la presencia de veteranos dibujantes como Gaietà Cornet i Joan Junceda), surgió como un intento periodístico de contrarrestar el éxito electoral de Esquerra Republicana de Catalunya (ERC), un partido que a pesar de ser creado sólo un mes antes de las elecciones municipales de abril de 1931, consiguió una gran victoria política. Si bien durante los primeros meses la revista mostró una explícita simpatía por la figura de Francesc Macià, líder de ERC, posteriormente adoptó una actitud muy crítica, hasta el punto de que si por algo destacó $D I C$ fue por sus duras críticas a ERC y su gestión en el poder.

La tesis centra su atención en tres temáticas concretas: el conflicto entre laicismo y catolicismo, el problema militar y el afán político por parte del Ejército, y, finalmente, la cuestión autonómica catalana. Se trata de tres cuestiones capitales que atraviesan toda la etapa republicana y que tuvieron un abundante reflejo en las páginas de las revistas satíricas. El seguimiento de la actualidad política a través de estas publicaciones arroja nueva luz sobre dichas temáticas, al mismo tiempo que pone de manifiesto la influencia de las revistas satíricas en el discurso político durante la Segunda República.

Dado el peso social e ideológico que tradicionalmente la Iglesia ha tenido en la sociedad española, las problemáticas relaciones entre la misma y el Estado se prolongaron desde el comienzo de la Segunda República hasta el inicio de la guerra civil. La aprobación de la Constitución, con artículos que prohibían las actividades educativas y comerciales por parte de las asociaciones religiosas, abrió la puerta a un enfrentamiento entre laicos y religiosos que tuvo su reflejo en las revistas satíricas. Así, mientras $\mathrm{El} \mathrm{Be}$ Negre bromeaba continuamente con estas restricciones legislativas, Gracia y Justicia y $D I C$ se convirtieron en firmes defensores del catolicismo, en especial en relación con la educación. Este posicionamiento fuertemente católico por parte de dichas revistas también estuvo acompañado por un persistente discurso antimasónico que se vinculaba directamente con la acción política de los partidos políticos de izquierdas.

En el ámbito de la problemática militar, las reformas azañistas, que perseguían la modernización del Ejército, así como poner fin al intervencionismo militar en política, también cosecharon partidarios y adversarios entre las publicaciones humorísticas. Las revistas con un perfil de izquierdas (como El Be Negre) alabaron las medidas emprendidas por Azaña, a quien acostumbraban a presentar como un político valiente que no vacilaba a la hora de restringir la acción castrense en la sociedad de la época. En contraste, Gracia y Justicia mantenía un fuerte perfil militarista, como la mayoría de las revistas conservadoras, tacharon a Azaña de «dictador» y «antiespañol».

Finalmente, en relación con la cuestión catalana, que se concretó en el Estatuto de Autonomía de 1932, las publicaciones se posicionaron de manera muy divergente. La adecuación del Estatuto de Núria, impulsado desde Cataluña y que cosechó un abrumador apoyo de la población catalana en agosto de 1931, a la normativa constitucional generó polémicas muy diversas. Mientras El Be Negre y DIC mostraron un apoyo indiscutible a la consecución de la 
autonomía (a pesar de los recortes que sufrió el texto final), con repetidas loas a la figura filocatalanista de Azaña, Gracia y Justicia, por su parte, no se cansó de exhibir una postura antiautonomista y anticatalanista. Esta oposición al Estatuto tuvo también el respaldo de otras publicaciones conservadoras, de la mayoría del Partido Socialista, así como de figuras influyentes como Miguel de Unamuno o José Ortega y Gasset.

En resumen, el contraste ideológico entre las revistas satíricas permite configurar una interpretación alternativa de los hechos que tuvieron lugar entre 1931 y 1936 . Las revistas satíricas, a pesar de su intención humorística, contribuyeron sin duda a la confrontación ideológica. El estallido de la guerra civil en 1936 supuso el fin de esta dialéctica gráfica, pero no de la dialéctica discursiva que se prolongó más allá de las propias revistas, desaparecidas en este año. Así, el discurso ideológico de Gracia y Justicia, en su sentido católico (como el que también defendía $D I C$ ), militarista y autoritario triunfó con la dictadura franquista, a partir de 1939.

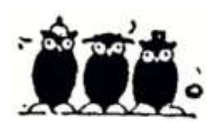

La Segunda República en el cine de ficción: Memoria, imagen e historia ${ }^{1}$

\section{Igor BARRENECHEA MARAÑÓN}

La presente tesis doctoral, dirigida por el catedrático de Historia Contemporánea Santiago de Pablo, es un estudio de cómo ha sido representada y retratada la memoria de la Segunda República española (19311936) por parte de la cinematografía española, centrándose exclusivamente en el cine de ficción y dejando a un lado tanto el cine documental, así como las producciones destinadas a la televisión.

En las últimas décadas, diversos historiadores españoles (Caparrós, Crusells, Hueso, De Pablo) y extranjeros (Rosenstone, Ferro, Sorlin, Sand) han abierto nuevas vías de investigación, desvelando la importancia del cine como fuente histórica y como nueva forma de escribir la Historia, además de profundizar en su influencia en la conformación de mentalidades, de la memoria y del imaginario colectivo. En muy poco tiempo, la relación HistoriaCine se ha convertido en un campo de investigación de enorme interés y en una disciplina de estudio que se ha añadido al currículum universitario.

Sin embargo, todavía hay grandes temas sin estudiar. Es el caso de la visión que el cine ha transmitido del período histórico de la Segunda República española hasta 1936, que (a diferencia del posterior de la Guerra Civil) apenas ha sido abordado, a pesar de ser uno de las etapas claves de la historia de España en el siglo XX. Esta tesis

1 Tesis doctoral defendida el 3 de marzo de 2014 en la Facultad de Letras de la Universidad del País Vasco en Vitoria-Gasteiz. Director: Santiago de Pablo Contreras (U. del País Vasco). Tribunal: Presidente: José Luis de la Granja (U. del País Vasco). Secretaria: Susana Serrano (U. del País Vasco). Vocales: Ángel Luis Hueso (U. de Santiago de Compostela), Amparo Martinez (U. de Zaragoza) y Magi Crusells (Centro de Investigaciones Film-Historia). 